\title{
Câncer em neovagina de mulheres trans: uma revisão sistemática
}

\author{
Neovagina cancer in trans women: a systematic review \\ Cáncer de neovagina en mujeres trans: una revisión sistemática
}

Recebido: 14/09/2021 | Revisado: 19/09/2021 | Aceito: 21/09/2021 | Publicado: 23/09/2021

\author{
Janaina Pinto Janini \\ ORCID: https://orcid.org/0000-0003-2781-7427 \\ Instituto Estadual de Diabetes e Endocrinologia Luiz Capriglioni, Brasil \\ E-mail: jjanini40@gmail.com \\ Lívia Migowski \\ ORCID: https://orcid.org/0000-0002-0296-4925 \\ Universidade Federal do Rio de Janeiro, Brasil \\ E-mail: liviamigowski@yahoo.com.br
}

\begin{abstract}
Resumo
Objetivo: descrever o processo de rastreio em mulheres transexuais com neoplasia que realizam vaginoplastia e os fatores de risco associados. Metodologia: revisão sistemática feita em bases nacionais e internacionais, com descritores transgender, neovagina, neoplasia, câncer e carcinoma, articulados pelos boleadores AND e OR, que geraram a seleção final de 7 artigos internacionais. Resultados: Evidenciou-se que as mulheres transexuais utilizaram a técnica com tecido peniano e escrotal, com idade superior a 43,75 anos e tempo de cirurgia entre 20 e 40 anos de cirurgia. Todas apresentaram adenocarcinoma espinocelular, sendo a maioria associada a infecção por papiloma vírus. Entre os sintomas pélvicos encontrados destacam-se dor, secreção sanguinolenta e de odor fétido e a detecção de uma massa tecidual no introito e no interior da neovagina. Os exames foram coletados por meio de biopsia ou esfregaço para análise citopatológica e testagem microbiológica. Considerações finais: Faz-se necessário a avaliação periódica das mulheres transexuais redesignadas com intuito de promover a saúde sexual e a prevenção ou detecção precoce de neoplasia neovaginal.
\end{abstract}

Palavras-chave: Neoplasias; Saúde de mulher; Pessoas gênero.

\begin{abstract}
Objective: to describe the screening process in transsexual women with cancer undergoing vaginoplasty and the associated risk factors. Methodology: systematic review carried out in national and international databases, with descriptors transgender, neovagina, neoplasm, cancer and carcinoma, articulated by the AND and OR rounders, which generated the final selection of 7 international articles. Results: It was evidenced that transsexual women used the technique with penile and scrotal tissue, aged over 43.75 years and surgery time between 20 and 40 years of surgery. All had squamous cell adenocarcinoma, most of which were associated with papillomavirus infection. Among the pelvic symptoms found, pain, bloody secretion and foul smelling stand out, and the detection of a tissue mass in the introitus and inside the neovagina. The exams were collected through biopsy or smear for cytopathological analysis and microbiological testing. Final considerations: Periodic evaluation of redesignated transsexual women is necessary in order to promote sexual health and the prevention or early detection of neovaginal neoplasia.
\end{abstract}

Keywords: Neoplasms; Women's health; People gender.

\section{Resumen}

Objetivo: describir el proceso de cribado en mujeres transexuales con cáncer sometidas a vaginoplastia y los factores de riesgo asociados. Metodología: revisión sistemática realizada en bases de datos nacionales e internacionales, con descriptores transgénero, neovagina, neoplasia, cáncer y carcinoma, articulados por las rondas AND y OR, que generó la selección final de 7 artículos internacionales. Resultados: Se evidenció que las mujeres transexuales utilizaron la técnica con tejido peneano y escrotal, con edad superior a 43,75 años y tiempo quirúrgico entre 20 y 40 años de la cirugía. Todos tenían adenocarcinoma de células escamosas, la mayoría de los cuales estaban asociados con la infección por virus del papiloma. Entre los síntomas pélvicos encontrados destacan el dolor, la secreción sanguinolenta y el mal olor, y la detección de una masa tisular en el introito y en el interior de la neovagina. Los exámenes se recolectaron mediante biopsia o frotis para análisis citopatológico y pruebas microbiológicas. Consideraciones finales: La evaluación periódica de las mujeres transexuales redesignadas es necesaria para promover la salud sexual y la prevención o detección temprana de neoplasias neovaginales.

Palabras clave: Neoplasias; La salud de la mujer; Género de personas. 


\section{Introdução}

A cirurgia de readequação de gênero, também conhecida como vaginoplastia, pode ser fundamental para transição física de mulheres transexuais, condição em que possuem identidade de gênero feminina e sexo de nascimento masculino(Janini et al., 2019; Janini \& Santos, 2020; Pariser \& Kim, 2019). A vaginoplastia é uma técnica útil disponibilizada via política de saúde do Processo transexualizador(Brasil, 2008, 2013b) para as usuárias que sentem incômodo falocêntrico, oferece a oportunidade de remoção da genitália masculina e uma aparência de gênero congruente a sua identidade de gênero (Pariser \& Kim, 2019).

O principal objetivo da vaginoplastia, além da adequação de gênero a mulheres transexuais que entendam tal demanda como essencial para sua transição, é criar um canal vaginal funcional, com diâmetro e comprimento adequados, preferencialmente lubrificada, capaz de promover a qualidade de vida sexual (Georgas et al., 2018).

Embora tenha uma utilização mais recente em mulheres transexuais, autores estimam seu uso desde 1817 para correção cirúrgica de agenesias em mulheres cisgêneras como a síndrome de Mayer-Rokitansky-Küster-Hauser, alterações no desenvolvimento sexual ou mulheres com perda tecidual por câncer com a utilização de variáveis técnicas para fins de avaliação de melhor efetividade e qualidade da vida sexual. Utiliza-se desde enxertos de pele não genital, retalhos de pele genital ou não genital até transplantes intestinais pediculados. Atualmente as abordagens se padronizaram, sendo as mais utilizadas para a vaginoplastia de mulheres transexuais técnicas com retalho peniano e com enxerto de sigmoide(Grosse et al., 2017; Pariser \& Kim, 2019; Willemsen \& Kluivers, 2015).

Geralmente a técnica mais adotada em mulheres transexuais é a combinação de retalho peniano com escrotal(Pariser \& Kim, 2019). Já a vaginoplastia com enxerto intestinal é o método preferido para o tratamento de doenças congênitas de agenesia vaginal ou em vaginosplastia secundária, ou seja, quando se torna necessário refazer o procedimento, nos casos de penectomia com perda tecidual ou em casos de hipoplasia/falta de tecido peniano que impossibilite a construção de uma neovagina funcional(Grosse et al., 2017).

Acredita-se que o primeiro registro vaginoplastia de enxerto intestinal em mulheres cisgêneras tenha ocorrido em 1892 usando o reto e em 1904 usando o íleo, mas em mulheres transexuais somente em 1974, objetivando atender o desejo de alteração física e qualidade da vida sexual das mesmas(Georgas et al., 2018).

A utilização de tecidos de forma análoga ao proposto fisiologicamente tem desvantagens, como a produção contínua de muco, o risco futuro de colite e até câncer. Contudo o monitoramento deficiente dificulta a detecção e investigação de ocorrências. O primeiro caso de câncer neovaginal em mulheres transexuais foi registrado em 2001(Georgas et al., 2018).

Isso reflete na necessidade da construção de conhecimento acerca da questão, com desenvolvimento e acompanhamento de protocolos, como ferramentas capazes de registrar efetividade dos procedimentos, resultados encontrados e complicações(Georgas et al., 2018).

No Brasil, a Política Nacional de Saúde da Mulher preconiza o rastreio do câncer de colo uterino associado a infecção pelo papilomavírus humano (HPV) oncogênico(Brasil, 2004), Infecção Sexualmente Transmissível (IST) e precursor de doença inflamatória pélvica.

Destaca-se o protagonismo de alguns subtipos de HPV, como causadores de câncer. As mulheres transexuais não possuem colo uterino, mas possuem canal vaginal que também pode ser propenso ao câncer. Diferente da mulher cisgênera, cujo tecido vaginal é natural do aparelho sexual-reprodutor, consta inferioridade estatística aplicada ao câncer de vagina e ausência de protocolo de rastreio por não ser um câncer frequente(Brasil, 2004), diferentemente da mulher trans submetida a vaginoplastia, haja vista fatores de risco existentes.

Ainda nas IST, tem aumentado o quantitativo de neoplasias, dentre elas o carcinoma hepatocelular (pela hepatite B), o carcinoma da vulva, do pênis, do ânus (por alguns subtipos de HPV, pelo vírus da imunodeficiência humana-HIV) e o sarcoma 
de Kaposi (HIV). Assim a prevenção e controle eficazes das IST são considerados como uma prioridade para a promoção da saúde sexual, estão relacionadas com alguns tipos de cânceres em mulheres (Brasil, 2004).

Na política Nacional das Lésbicas, Gays, Bissexuais e Travestis e Transexuais-LGBT observa-se o objetivo de prevenir novos casos de câncer de próstata em mulheres transexuais, mas não cita o rastreio de câncer neovagina, apenas estimula o aperfeiçoamento das tecnologias de cuidado na política do processo transexualizador, para mulheres transexuais (Brasil, 2013a).

Essas tecnologias deveriam ser voltadas às intervenções feitas nos corpos para adequação à identidade gênero como a vaginoplastia, que deve atender aos quesitos estético, funcional e salutar, ações complexas diante da variedade de técnicas cirúrgicas de vaginoplastia pela utilização diferenciada de tecidos para confecção do canal vaginal, que pode ocasionar diferentes respostas a exposição desses tecidos a estressores químicos, físicos e infecciosos.

Em se tratando de uma população com invisibilidade, o acompanhamento da neovagina por meio de consulta ginecológica, acaba sendo descartado, não somente pela política de saúde da mulher excludente, mas pela baixa estatística de câncer de vagina de mulheres cisgêneras (Brasil, 2004)' que induz o entendimento de que a investigação de (neo)vaginas pode não ser prioritária .

Além da invisibilidade social e programática dos sistemas de saúde e politicas publicas excludentes, a multiplicidade de técnicas cirúrgicas possíveis para a vaginoplastia, dificulta a unificação de padrões para os achados citológicos, que dependem do tipo de tecido utilizado para a reconstrução vaginal (Grosse et al., 2017).

Tendo em vista a exposição feita, este artigo busca descrever o processo de rastreio em mulheres transexuais com neoplasia que realizam vaginoplastia e os fatores de risco associados.

\section{Metodologia}

Trata-se de uma revisão sistemática cuja proposta incorpora propósitos como a definição de conceitos, teorias e evidências aplicados a um determinado cenário. Assim, pode-se sintetizar lacunas de conhecimento, a partir das produções existentes e aplicação de resultados desses estudos na prática(Souza et al., 2017).

A revisão sistemática da literatura consiste na síntese de estudos primários que contém objetivos, materiais e métodos claramente definidos, analisados através de metodologia clara e reproduzível. Para sua efetivação foram cumpridas as seguintes etapas:1) identificação do tema e seleção da hipótese; 2) determinação dos critérios para inclusão e exclusão de estudos/amostragem ou pesquisa de literatura; 3) delimitação das informações a serem investigadas e categorização dos estudos selecionados; 4) avaliação dos estudos incluídos na revisão; 5) interpretação dos resultados e, 6) apresentação da revisão(Souza et al., 2017).

$\mathrm{O}$ estudo parte da hipótese de que as mulheres transexuais submetidas a vaginoplastia possuem como fator de risco o desenvolvimento de câncer de neovagina. A busca dos artigos consistiu em consulta às principais bases de dados da PUBMED, Medical Literature Analysis and Retrievel System Online (MEDLINE) e na Literatura Latino-Americana e do Caribe em Ciências da Saúde (LILACS), que utilizou os descritores transgender, neovagina, neoplasia e câncer e carcinoma, articulados pelos boleadores AND e OR. Foram selecionados 9 artigos na PUBMED, 8 na MEDLINE e 1 LILACS , totalizando 18 artigos (Tabela 1).Os critérios de inclusão foram o recorte temporal nos últimos dez anos, de 2011 a 2021, e que abordem o tema carcinoma em mulheres transexuais submetidas a vaginoplastia, onde todos deverão responder a, no mínimo 10 dos 11 itens investigados. O critério de exclusão foram artigos de reflexão e cartas ao editor. 
Tabela 1 - Artigos selecionados para a revisão sistemática da literatura.

\begin{tabular}{|l|c|c|c|c|c|c|}
\hline $\begin{array}{l}\text { Método de busca de artigos em base de } \\
\text { dados }\end{array}$ & Pubmed & Medline & Lilacs & Repetidos & Descartados & Total \\
\hline $\begin{array}{l}\text { transgender AND neovagina AND } \\
\text { (Neoplasms OR câncer OR carcinoma) }\end{array}$ & 9 & 8 & 1 & 9 & 2 & 7 \\
\hline
\end{tabular}

Fonte: Autores.

As informações primárias investigadas foram: autores, título do artigo, periódico, base de dados ancorados, amostra, idade das participantes, tempo de cirurgia das mulheres, técnica cirúrgica empregada, sintomas pélvicos, técnica de coleta e qualidade de amostragem, detecção de HPV, outras ISTs, neoplasias e alterações celulares. Após a busca dos artigos nas bases de dados, foi realizada a leitura flutuante a fim de identificar os critérios de inclusão. Dos 18 artigos selecionados, 9 eram repetidos e foram excluídos, restando 9 artigos. Desses apenas dois não atendiam o critério de inclusão, pois não continham os dados a serem investigados, onde um era de câncer anal em mulher transexual e o outro não abordava detecção de neoplasia neovaginal. Finalizou-se a pesquisa com a seleção de 7 artigos.

Tabela 2 - Apresentação dos artigos selecionados.

\begin{tabular}{|c|c|c|c|c|}
\hline $\mathbf{n}$ & Autores & Título do artigo & Periódico & $\begin{array}{l}\text { Base de } \\
\text { dados }\end{array}$ \\
\hline 1 & $\begin{array}{l}\text { Grosse A, Grosse C, } \\
\text { Lenggenhager D, Bode B, } \\
\text { Camenisch U, Bode P. }\end{array}$ & $\begin{array}{l}\text { Cytology of the neovagina in transgender } \\
\text { women and individuals with congenital } \\
\text { or acquired absence of a natural vagina }\end{array}$ & $\begin{array}{l}\text { Cytopathology. } 2017 \\
\text { Jun; 28(3):184-191. }\end{array}$ & $\begin{array}{l}\text { Pubmed; } \\
\text { Medline }\end{array}$ \\
\hline 2 & $\begin{array}{l}\text { Fernandes HM; Manolitsas TP; } \\
\text { Joblin TW. }\end{array}$ & $\begin{array}{l}\text { Carcinoma of the neovagina after male- } \\
\text { to-female reassignment. }\end{array}$ & $\begin{array}{l}\text { J Low Genit Tract } \\
\text { Dis;18(2): E43-5, } 2014 \\
\text { Apr. }\end{array}$ & $\begin{array}{l}\text { Pubmed; } \\
\text { Medline }\end{array}$ \\
\hline 3 & $\begin{array}{l}\text { Bollo J; Balla A; Rodriguez LC; } \\
\text { Martinez C; Quaresima S; } \\
\text { Targarona EM. }\end{array}$ & $\begin{array}{l}\text { HPV-related squamous cell carcinoma in } \\
\text { a neovagina after male-to-female gender } \\
\text { confirmation surgery. }\end{array}$ & $\begin{array}{l}\text { Int J STD AIDS;29(3): } \\
\text { 306-308, } 201803 .\end{array}$ & $\begin{array}{l}\text { Pubmed; } \\
\text { Lilacs }\end{array}$ \\
\hline 4 & $\begin{array}{l}\text { Trum HW; Hoebeke P; Gooren } \\
\text { LJ. }\end{array}$ & $\begin{array}{l}\text { Sex reassignment of transsexual people } \\
\text { from a gynecologist's and urologist's } \\
\text { perspective }\end{array}$ & $\begin{array}{l}\text { Acta Obstet Gynecol } \\
\text { Scand; 94(6): 563-7, } \\
\text { 2015 Jun. }\end{array}$ & $\begin{array}{l}\text { Pubmed; } \\
\text { Medline }\end{array}$ \\
\hline 5 & $\begin{array}{l}\text { Wang G, Ferguson D, Ionescu } \\
\text { DN, Hoang L, Barrett S, van } \\
\text { Niekerk D, Rose JN, } \\
\text { Kollmannsberger C. }\end{array}$ & $\begin{array}{l}\text { HPV-Related Neovaginal Squamous Cell } \\
\text { Carcinoma Presenting as Lung } \\
\text { Metastasis after Male-to-Female Gender } \\
\text { Confirmation Surgery. Case Rep }\end{array}$ & $\begin{array}{l}\text { Oncol. 2020 Jan } \\
\text { 20;13(1):17-22 }\end{array}$ & $\begin{array}{l}\text { Pubmed; } \\
\text { Medline }\end{array}$ \\
\hline 6 & $\begin{array}{l}\text { Uaamnuichai S; Panyakhamlerd K; } \\
\text { Suwan A; Suwajo P; Phanuphak N; } \\
\text { Ariyasriwatana C; Janamnuaysook } \\
\text { R; Teeratakulpisarn N; Vasuratna } \\
\text { A; Taechakraichana N. }\end{array}$ & $\begin{array}{l}\text { Neovaginal and anal high-risk human } \\
\text { papillomavirus DNA among } \\
\text { Thai transgender women in gender-health } \\
\text { clinics. }\end{array}$ & $\begin{array}{l}\text { Sex Transm Dis. } 2021 \\
\text { Feb } 1 .\end{array}$ & $\begin{array}{l}\text { Pubmed; } \\
\text { Medline }\end{array}$ \\
\hline 7 & Fierz R, Ghisu GP, Fink D. & $\begin{array}{l}\text { Squamous Carcinoma of the neovagina } \\
\text { after Male-to-Female Reconstruction } \\
\text { Surgery: A Case Report and Review of } \\
\text { the Literature Case }\end{array}$ & $\begin{array}{l}\text { Rep Obstet Gynecol. } \\
\text { 2019 Jan } \\
\text { 16;2019:4820396. }\end{array}$ & $\begin{array}{l}\text { Pubmed; } \\
\text { Medline }\end{array}$ \\
\hline
\end{tabular}

Fonte: Autores (2021). 


\section{Resultados e Discussão}

Independentemente da técnica utilizada para a vaginoplastia, a criação de uma neovagina resulta na exposição do tecido transplantado a condições anormais, tanto internas como hormonioterapia, e externas como traumas, colonização por microorganismos e contato com substâncias como esperma e lubrificante. Ainda assim poucos estudos determinam o impacto de tais exposições aos tecidos implantados (Grosse et al., 2017).

Todos os artigos sete (100\%) selecionados possuíam autoria, periódicos e bases de dados internacionais, o que pode representar a carência de estudos nacionais sobre a saúde sexual de mulheres transexuais, ainda que se tenha a política pública de saúde como o processo transexualizador que inclui a vaginoplastia como ação de intervenção para a transição física, procedimento esse que gera uma neovagina. Quatro artigos (71,5\%) (Bollo et al., 2018; Fernandes et al., 2014; Fierz et al., 2019; Wang et al., 2020) tinham no título explicitado o estudo de carcinoma neovaginal, sendo um (14,3\%) (Wang et al., 2020) com caso confirmado de metástase a partir do carcinoma espinocelular e três artigos (28,6\%) (Bollo et al., 2018; Uaamnuichai et al., 2021; Wang et al., 2020) com Papilomavírus Humano como fator de risco para o desenvolvimento de lesões na neovagina. Apenas um (14,3\%) artigo (Trum et al., 2015) mencionou o olhar ginecológico para mulheres submetidas a vaginoplastia.

Foram coletados exames com 74 mulheres transexuais com idade média de 48,73 e mediana de 43,75 anos. A técnica empregada determinou faixas etárias diferentes de acometimento para a detecção de carcinomas, sendo mais precoce as intestinais, entre 20 e 40 anos e as vaginoplastias penianas após 40 anos(Grosse et al., 2017). Esses dados podem ser considerados um importante parâmetro temporal, orientador para ações de rastreio para neoplasias, o que não descarta a importância de investigação em idades anteriores (Tabela 3).

Tabela 3 - Apresentação do número de mulheres transexuais com vaginoplastias estudadas, tempo de cirurgia, presença de sintomas pélvicos, técnicas cirúrgicas empregadas, exames de rastreio realizados, presença de IST e Neoplasia neovaginal.

\begin{tabular}{|c|c|c|c|c|c|c|c|c|}
\hline Artigo & $\begin{array}{l}\text { Numero de } \\
\text { participantes }\end{array}$ & $\begin{array}{l}\text { Idade } \\
\text { média }\end{array}$ & $\begin{array}{c}\text { Tempo de } \\
\text { cirurgia }\end{array}$ & $\begin{array}{c}\text { Sintoma } \\
\text { pélvico }\end{array}$ & $\begin{array}{l}\text { Técnica } \\
\text { cirúrgica }\end{array}$ & $\begin{array}{c}\text { Exames } \\
\text { realizados }\end{array}$ & Neoplasia & IST \\
\hline A1 & 12 & 43,75 & $20-40$ anos & $\operatorname{sim}$ & $\begin{array}{l}9 \mathrm{RPE}^{1} \\
2 \mathrm{SG}^{1} \\
1 \mathrm{TNG}^{1}\end{array}$ & $\begin{array}{l}\text { Esfregaço } \\
\mathrm{PCR}^{2}\end{array}$ & $\begin{array}{l}\text { carcinoma } \\
\text { espinocelular }\end{array}$ & HPV \\
\hline $\mathrm{A} 2$ & 1 & 53 & 33 & $\operatorname{sim}$ & RPE & $\begin{array}{l}\text { Biópsia } \\
\text { Estudo da } \\
\text { expressão da } \\
\text { proteina } 16\end{array}$ & $\begin{array}{l}\text { carcinoma } \\
\text { espinocelular }\end{array}$ & Ausente \\
\hline A3 & 1 & 78 & 45 & $\operatorname{sim}$ & RPE & $\begin{array}{l}\text { Biópia } \\
\text { PCR }\end{array}$ & $\begin{array}{l}\text { carcinoma } \\
\text { espinocelular }\end{array}$ & HPV \\
\hline A4 & 1 & 24 & 18 & $\operatorname{sim}$ & RPE & $\begin{array}{l}\text { Esfregaço } \\
\text { PCR }\end{array}$ & $\begin{array}{l}\text { carcinoma de } \\
\text { células escamosas }\end{array}$ & HPV \\
\hline A5 & 1 & 69 & 44 & não & RPE & $\begin{array}{l}\text { Biópsia e } \\
\text { hibridização } \\
\text { molecular }\end{array}$ & $\begin{array}{l}\text { carcinoma } \\
\text { espinocelular com } \\
\text { metastase } \\
\text { pulmonar }\end{array}$ & HPV \\
\hline A6 & 57 & 30,4 & 34 & $\operatorname{sim}$ & RPE & $\begin{array}{l}\text { Esfregaço } \\
\mathrm{PCR}^{2-3}\end{array}$ & $\begin{array}{l}\text { células escamosas } \\
\text { irregulares }\end{array}$ & $\begin{array}{l}\text { HIV; } \\
\text { HPV }\end{array}$ \\
\hline A7 & 1 & 43 & 23 & $\operatorname{sim}$ & RPE & $\begin{array}{l}\text { Esfregaço } \\
\mathrm{PCR}^{2}\end{array}$ & $\begin{array}{l}\text { carcinoma } \\
\text { espinocelular }\end{array}$ & HPV \\
\hline
\end{tabular}

1-RPE- Retalho de pênis e escroto; , SG,- sigmoide; TNGTecido não genital

2-Reação da transcriptase reversa seguida pela reação em cadeia da polimerase

3- De 35 amostras válidas de 57 neovaginais, 8 (20\%) testaram positivo para DNA de hrHPV. De 30 válidas de 57 amostras anais, 6 (19,4\%) testaram positivo para DNA de hrHPV.

Fonte: Autores (2021). 
Das 74 cirurgias de confirmação de gênero foram utilizados retalho de tecido peniano e da bolsa escrotal em 71 (95,9\%)(Bollo et al., 2018; Fernandes et al., 2014; Fierz et al., 2019; Grosse et al., 2017; Trum et al., 2015; Uaamnuichai et al., 2021; Wang et al., 2020), tecido epitelial não genital em 1(1,4\%)(Grosse et al., 2017) e sigmóide em 2 (2,7\%) mulheres trans(Grosse et al., 2017). O período de latência entre a idade na reconstrução e a idade do diagnóstico de câncer foi entre 20 a 44 anos após a realização da vaginoplastia, mediana de 33 anos, podendo considerar uma idade de corte (idade determinante) para o aparecimento de neoplasias neovaginais, devendo ocorrer então a diminuição do intervalo do monitoramento a partir desse tempo.

A maior parte dos estudos (85\%) registrou que as mulheres transexuais com neoplasia neovaginal apresentam sintomas pélvicos (tabela 3). Três artigos (Bollo et al., 2018; Fierz et al., 2019; Grosse et al., 2017) identificaram dor, processo inflamatório local (Fierz et al., 2019; Grosse et al., 2017; Trum et al., 2015) e odor fétido(Fernandes et al., 2014; Fierz et al., 2019; Grosse et al., 2017), corrimento vaginal sanguinolento(Bollo et al., 2018; Fernandes et al., 2014; Fierz et al., 2019) e presença de massa tumoral(Bollo et al., 2018; Fernandes et al., 2014; Trum et al., 2015). Dois artigos identificaram micro lesões neovaginais (Bollo et al., 2018; Grosse et al., 2017),corrimento vaginal claro(Fernandes et al., 2014; Grosse et al., 2017) e fístula anal (Bollo et al., 2018; Trum et al., 2015). Lesão no intróito vaginal(Bollo et al., 2018) foi referenciado por um artigo (tabela 4) e associado processo inflamatório em um estudo(14,3\%) com a presença de HPV e a outras IST em 8 mulheres transexuais estudadas(Grosse et al., 2017). Pensando-se na correlação com carcinoma espinocelular, ocorrem manifestações clínicas como lesões ulceradas, prurido, odor fétido, sangramento e glanglionamento inguinal(Bezerra et al., 2020; Wind et al., 2019).

Tabela 4 - Apresentação dos sintomas pélvicos em mulheres transexuais com neoplasia neovaginal.

\begin{tabular}{|c|c|c|c|c|c|c|c|}
\hline Sintomas pélvicos & A1 & A2 & A3 & A4 & $\mathbf{A 5}$ & A6 & A7 \\
\hline Micro-lesão por relação sexual ou uso do modelador & $\mathbf{x}$ & & $\mathbf{x}$ & & & & \\
\hline Corrimento vaginal inicial claro & $\mathbf{x}$ & $\mathbf{x}$ & & & & $\mathbf{x}$ & \\
\hline Corrimento vaginal sanguinolento ou sangramento & & $\mathrm{x}$ & & & & $\mathrm{x}$ & $\mathrm{x}$ \\
\hline Corrimento com odor fétido & $\mathbf{x}$ & $\mathbf{x}$ & & & & & $\mathbf{x}$ \\
\hline Processo inflamatório local ${ }^{1}$ & $\mathbf{x}$ & & & $\mathbf{x}$ & & & $\mathbf{x}$ \\
\hline Dor & $\mathbf{x}$ & & $\mathbf{x}$ & & & & $\mathbf{x}$ \\
\hline Lesão no introito vaginal & & & $\mathbf{x}$ & & & & \\
\hline Fístula & & & $\mathbf{x}$ & $\mathbf{x}$ & & & \\
\hline Massa tumoral & & $\mathbf{x}$ & $\mathbf{x}$ & & $\mathbf{x}$ & & \\
\hline
\end{tabular}

1- pelo uso inadequado do modelador. Fonte: Autores (2021).

Dos casos relatados anteriormente, nos quais as pacientes apresentavam um ou mais tipo de sintomas, apenas uma paciente não apresentou sintomas pélvicos (Wang et al., 2020).

Todos os artigos informaram a realização de coleta de material citológico. No caderno de referência de citopatologia não ginecológica utilizado para capacitação e profissionais de nível médio em saúde pelo Ministério da Saúde, os espécimes citopatológicos apresentam-se em dois grandes grupos, que tomam como base a técnica utilizada para coleta de amostras. A primeira enquadra-se nas amostras coletadas por punção aspirativa com agulha fina (PAAF) ou por capilaridade.

A segunda técnica consiste na raspagem tecidual lesionada ou em processo de descamação natural como raspados de superfícies cutâneas ou mucosas, como pele, boca, uretra, canal anal, extraídos por meio de lâminas de bisturi, swabs, espátulas ou escovas apropriadas(Brasil, 2012). Os escovados intestinais também são utilizados para identificar lesões que, em seu ambiente original, são feitos via sondagem, o que não é necessário nas mulheres transexuais pela exposição do tecido na cavidade neovaginal(Brasil, 2012). Nesse caso, adota-se o mesmo princípio para coleta de material em mulheres cisgêneras. 
Nos 7 artigos analisados foram realizados raspados em 71 mulheres transexuais com tecido peniano, 1 de tecido dérmico e 2 de enxerto de sigmóide.

Os achados identificados foram alterações celulares atípicas e carcinoma neovaginais. Considerando o número de 12 mulheres transexuais, dois artigos encontraram (16,6\%) raspados foram identificados com células escamosas atípicas de significado indeterminado e um (8,3\%) como lesão intraepitelial escamosa de alto grau (Bezerra et al., 2020; Fierz et al., 2019b; Grosse et al., 2017). Em uma correlação ao câncer de pênis, tecido do enxerto utilizado na neovagina, ocorre em mais de $10 \%$ nos estados das regiões nordeste e $35 \%$ no sudeste do Brasil, sendo o mais comum o carcinoma espinocelular, também conhecido como carcinoma de células escamosas ou escamocelular) identificado em todos os estudos (Carmo, 2020; Korkes et al., 2020). O carcinoma de células escamosas é o tipo de câncer peniano mais comum, sendo ainda mais frequente em populações com baixo nível socioeconômico, condições precárias de higiene e em homens cisgêneros com fimose (Carmo, 2020).

O câncer de espinocelular peniano, de acometimento agressivo, tem alta mortalidade entre os homens cisgêneros acometidos e por isso tem sido alvo de investimentos e estratégia de ação na Política Nacional de Atenção Integral a Saúde do Homem (PNAISH) no sentido de minimizar práticas de risco e promover o diagnóstico precoce da doença (Bezerra et al., 2020; Korkes et al., 2020). Além da vaginoplastia ser composta de tecido peniano e escrotal que constituem fatores de risco, tal qual para os homens cisgêneros, as mulheres transexuais possuem outros possíveis fatores de risco como processo incisional e inflamatório cirúrgico, fístulas intestinais causando depósito de fezes e acúmulo de sujidade no canal neovaginal, ações químicas e físicas diferentes da proposta original do retalho, lesões pela relação sexual, uso recorrente do dilatador para evitar a estenose do canal, exposição local a substancias químicas e/ou sêmen e hormonização (Bollo et al., 2018; Grosse et al., 2017; Trum et al., 2015).

Um artigo(14,3\%)referenciou a neovagina com enxerto de sigmóide em vaginoplastia com carcinoma de cólon sigmoidal, semelhante a achados em transplantes de intestino(Grosse et al., 2017a). Vaginoplastias de sigmóide possuem comprimento, textura, muco e estética parecidas com a vagina de mulher cisgênera. Por outro lado, a profundidade maior oferecida por essa técnica pode acarretar estase sanguínea e diminuição da umidade na parte mais interna da vagina, tendo complicações como colites de desvio e ulcerativa, peritonite, obstrução intestinal, neuroma juncional, adenocarcinoma, estenose introital, mucocele(Grosse et al., 2017). Ainda que o único estudo que tenha realizado exame citopatológico em neovaginas de sigmóide tenha encontrado células nucleadas colunares e ausência de adenocarcinoma, observaram nos dois casos analisados a existência de processo inflamatório, o que é um fator de risco para enfermidades já citadas como também para carcinogênese. Além disso, a mucosa do cólon é mais vulnerável e, portanto, mais susceptível a doenças sexualmente transmissíveis, incluindo HIV (Georgas et al., 2018; Grosse et al., 2017).

A escassez de estudos citopatológicos em neovaginas de sigmóide mostra a importância da realização de novos estudos para clarificar o perfil das mulheres transexuais acometidas bem como fatores de risco associados e desenvolvimento da doença.

No que tange a qualidade das amostras, foi descrito a presença de células escamosas anucleadas abundantes comum em amostras citológicas de neovaginas de retalho peniano, mesclada a quantidade significativa de resíduos celulares acumulados provenientes da queratinização e material produzido pelas glândulas sebáceas, consequência da preservação da característica tecidual original (Grosse et al., 2017). Da mesma forma, neovaginas de células intestinais acompanham grande quantidade de muco. Tais condições podem tornar as amostras insaturadas insatisfatórias, o que leva a necessidade de revisão do padrão satisfatório para amostras citológicas de neovaginais. De acordo com o indicador de qualidade Bethesda de 2014 uma amostra cervical de uma vagina cisgênera é considerada adequada com um mínimo de 5000 células epiteliais escamosas bem visualizadas. No entanto as amostras neovaginais podem não estar dentro desse parâmetro e conter células 
escamosas cobertas por muco, detritos ou com característica de processo inflamatório, e por isso consideradas equivocadamente insatisfatórias (Grosse et al., 2017).

O HPV constitui um fator de risco considerável de câncer de neovagina em mulheres transexuais. Vários graus de displasia, bem como carcinoma espinocelular foram descritos em rastreio de HPV-positivo de amostras obtidas de neovaginas revestidas peniana, que incluíram PCR (Grosse et al., 2017), captura hibrida (Wang et al., 2020) e expressão da proteína 16 (Wang et al., 2020).

O alto risco para desenvolvimento de câncer pode ocorrer antes mesmo da cirurgia, pois a prevalência do HPV é alta na região genital masculina, com estimativas médias de $76 \%$, o que é um problema a ser investido no processo de cuidado, já que a maioria da neovagina das mulheres transexuais é proveniente de enxertos de pele peniana e escrotal. Autores retratam estudo com deteç̧ão de HPV em $28 \%$ em amostras de prepúcio, $24 \%$ na haste do pênis e $16 \%$ em glande $31 \%$ de tecidos utilizados na vaginoplastia. No entanto, não há protocolos de rastreio em mulher transexual, seja pela ausência de políticas públicas inclusivas ou da compreensão de um cuidado continuo pós operatório para essas mulheres. Isso revela a importância da familiarização com a anatomia pélvica das mulheres transexuais para otimizar a interpretação e também a coleta de todas as informações clínicas para auxiliar no diagnóstico (Grosse et al., 2017; Wang et al., 2020).

As mulheres transexuais não portadoras do HPV, tem como fator de risco comportamentos sexuais sem uso de preservativo, pois a incapacidade reprodutiva diminui a preocupação com preservativos, tornando o HPV mais facilmente transmitido (Wang et al., 2020), o que mostra a importância do acompanhamento clínico, bem como orientações para saúde sexual dessa população.

No entanto, apenas um artigo(Wang et al., 2020) sinalizou a existência de acompanhamento regular ginecológico de apenas $4 \%$ de todas as mulheres transexuais após a conclusão da vaginoplastia. Além do acompanhamento ginecológico, recomendou-se esfregaço a cada 3 anos, a partir dos 21 anos de idade até os 70 anos para mulheres transexuais, inclusive com identificação de verrugas no exame ginecológico (Wang et al., 2020), as quais mediante a avaliação clínica e análise do histórico da usuária, pode ter intervalo diminuído. Tais casos igualmente levantam preocupações se as mulheres transexuais estão cientes do risco de desenvolvimento de câncer neovaginal e a necessidade de participar de programas de rastreamento de câncer (Grosse et al., 2017), de forma a protagonizar a busca pelos serviços de saúde para o rastreio precoce.

\section{Considerações Finais}

O estudo revelou que as mulheres transexuais que realizaram vaginoplastia podem desenvolver neoplasia. Ainda que a política de saúde das mulheres informe baixa incidência de câncer vaginal em mulheres cisgêneras, não se pode aplicar tal parâmetro à neovagina. Enquanto a política de saúde do homem detecta que o câncer de pênis atinge parte da população masculina e são alvo de atenção em saúde para prevenção, o mesmo tecido utilizado em uma das técnicas de vaginoplastia em mulheres transexuais não é monitorizado, ainda que possuam mesmos fatores de risco antes da cirurgia.

São poucos os estudos que envolvem investigação câncer de cólon sigmóide, que pode ter como justificativa a quantidade reduzida do uso da técnica quando comparada a de tecido peniano/ escrotal. Ademais, as qualidades das amostras recolhidas são comparadas com a ginecológica, não levando em consideração as características do tecido implantado, o que pode levar ao descarte ou análise indevida do material.

O HPV foi citado como um fator de risco para neoplasia em vaginoplastia e deve ser monitorado juntamente com a análise citológica tecidual, em exames ginecológicos periódicos, que devem ter protocolos de regularidade conforme o período de maior risco para doença. Condições de higienização, integridade da pele, secreção e outros sintomas pélvicos também devem ser monitorados pois podem ser fator de risco para acometimentos neoplásicos, bem como ocorrem em homens cisgêneros. 


\section{Referências}

Bezerra, A. J. A. de O., Francisco, C. C. da S., Carvalho, W. de O., Souza, C. L. de, Nascimento, C. E. da S., Barbosa, M. de F. L., \& Duque, M. A. A. (2020). Carcinoma de pênis e próstata: Impactos entre a prevenção e diagnóstico para população masculina / Penis and prostate carcinoma: impacts between prevention and diagnosis for male population. Brazilian Journal of Development, 6(10), 76087-76098. https://doi.org/10.34117/bjdv6n10-146

Bollo, J., Balla, A., Rodriguez Luppi, C., Martinez, C., Quaresima, S., \& Targarona, E. M. (2018a). HPV-related squamous cell carcinoma in a neovagina after male-to-female gender confirmation surgery. International Journal of STD \& AIDS, 29(3), 306-308. https://doi.org/10.1177/0956462417728856

Brasil (Org.). (2004). Ministério da Saúde. Política nacional de atenção integral à saúde da mulher: Princípios e diretrizes. Editora MS.

Brasil. (2008). Ministério da Saúde. Portaria n. 457, de 19 de agosto de 2008.Diario Geral da União, Brasília.

Brasil. (2012). Ministério da Saúde. Caderno de referência 2: Citopatologia não ginecológica. Ministério da Saúde.

Brasil. (2013a). Ministério da Saúde. Política Nacional de Saúde Integral de Lésbicas, Gays, Bissexuais, Travestis e Transexuais. Ministério da Saúde.

Brasil. (2013b). Ministério da Saúde. Portaria 2.803, de19 novembro de 2013. Redefine e amplia o Processo Transexualizador no Sistema Único de Saúde. Diário Oficial [da] República Federativa do Brasil, Brasília, DF, n. $225, \quad 21 \quad$ nov. $2013 a . \quad$ Seção $\quad$ I, $p . \quad 25$. http://bvsms.saude.gov.br/bvs/saudelegis/gm/2013/prt2803_19_11_2013.html

Carmo, C. E. F. do. (2020). Câncer de pênis: Perspectivas Experimentais e Clínicas, Inovações Biomédicas e Educação em Saúde (PECIBES) ISSN - 2594$9888,6(2), 33-35$.

Fierz, R., Ghisu, G.-P., \& Fink, D. (2019a). Squamous Carcinoma of the Neovagina after Male-to-Female Reconstruction Surgery: A Case Report and Review of the Literature. Case Reports in Obstetrics and Gynecology, 2019, 4820396. https://doi.org/10.1155/2019/4820396

Georgas, K., Belgrano, V., Andreasson, M., Elander, A., \& Selvaggi, G. (2018). Bowel vaginoplasty: A systematic review. Journal of Plastic Surgery and Hand Surgery, 52(5), 265-273. https://doi.org/10.1080/2000656X.2018.1482220

Grosse, A., Grosse, C., Lenggenhager, D., Bode, B., Camenisch, U., \& Bode, P. (2017a). Cytology of the neovagina in transgender women and individuals with congenital or acquired absence of a natural vagina. Cytopathology: Official Journal of the British Society for Clinical Cytology, 28(3), 184-191. https://doi.org/10.1111/cyt.12417

Janini, J. P., \& Santos, R. da S. (2020). Relações sócio-familiares e a construção da personalidade da pessoa transexual. Research, Society and Development, 9(9), e677997883-e677997883. https://doi.org/10.33448/rsd-v9i9.7883

Janini, J. P., Santos, R. da S., Santos, L. F. de M. dos, \& Souza, V. de M. (2019). The epistemological construction of transsexuality: The science, nursing and common sense. Escola Anna Nery, 23(3), e20180345. https://doi.org/10.1590/2177-9465-ean-2018-0345

Korkes, F., Rodrigues, A. F. S., Baccaglini, W., Cunha, F. T. S., Slongo, J., Spiess, P., \& Glina, S. (2020). Tendências e carga econômica do câncer de pênis no sistema público de saúde brasileiro. Einstein (São Paulo), 18. https://doi.org/10.31744/einstein_journal/2020AO5577

Pariser, J. J., \& Kim, N. (2019). Transgender vaginoplasty: Techniques and outcomes. Translational Andrology and Urology, 8(3), 241-247. https://doi.org/10.21037/tau.2019.06.03

Souza, L. M. M. de, Marques-Vieira, C. M. A., Severino, S. S. P., \& Antunes, A. V. (2017). A metodologia de revisão integrativa da literatura em enfermagem (http://www.sinaisvitais.pt/images/stories/Rie/RIE21.pdf\#page=17). 21(2), 17-26.

Trum, H. W., Hoebeke, P., \& Gooren, L. J. (2015). Sex reassignment of transsexual people from a gynecologist's and urologist's perspective. Acta Obstetricia Et Gynecologica Scandinavica, 94(6), 563-567. https://doi.org/10.1111/aogs.12618

Uaamnuichai, S., Panyakhamlerd, K., Suwan, A., Suwajo, P., Phanuphak, N., Ariyasriwatana, C., Janamnuaysook, R., Teeratakulpisarn, N., Vasuratna, A., \& Taechakraichana, N. (2021). Neovaginal and anal high-risk human papillomavirus DNA among Thai transgender women in gender-health clinics. Sexually Transmitted Diseases. https://doi.org/10.1097/OLQ.0000000000001388

Willemsen, W. N. P., \& Kluivers, K. B. (2015). Long-term results of vaginal construction with the use of Frank dilation and a peritoneal graft (Davydov procedure) in patients with Mayer-Rokitansky-Küster syndrome. Fertility and Sterility, 103(1), 220-227.e1. https://doi.org/10.1016/j.fertnstert.2014.10.014

Wind, M. M., Fernandes, L. M. S., Pinheiro, D. H. P., Ferreira, V. R., Gabriel, A. C. G., Correia, S. F., \& Silva, C. T. X. (2019). Câncer de pêni s: Aspectos epidemiológicos, psicológicos e fatores de risco / Penile cancer: epidemiological, psychological and risk factors. Brazilian Journal of Development, 5(9), 14613-14623. https://doi.org/10.34117/bjdv5n9-066 